\title{
Adhesion forces in the self-recognition of oligosaccharide epitopes of the proteoglycan aggregation factor of the marine sponge Microciona prolifera
}

\author{
Adriana Carvalho de Souza • Dragomir N. Ganchev • \\ Margot M. E. Snel • Jan P. J. M. van der Eerden • \\ Johannes F. G. Vliegenthart • Johannis P. Kamerling
}

Received: 20 June 2008 /Revised: 19 September 2008 / Accepted: 24 September 2008 / Published online: 9 October 2008

(C) The Author(s) 2008. This article is published with open access at Springerlink.com

\begin{abstract}
Cell aggregation in the marine sponge Microciona prolifera is mediated by a multimillion molecular-mass aggregation factor, termed MAF. Earlier investigations revealed that the cell aggregation activity of MAF depends on two functional domains: (i) a $\mathrm{Ca}^{2+}$-independent cellbinding domain and (ii) a $\mathrm{Ca}^{2+}$-dependent proteoglycan self-interaction domain. Structural analysis of involved carbohydrate fragments of the proteoglycan in the selfassociation established a sulfated disaccharide $\beta$-DGlc $p$ NAc3 $S$ - $(1 \rightarrow 3)-\alpha-\mathrm{L}-\mathrm{Fuc} p$ and a pyruvated trisaccharide $\beta$-D-Gal $p 4,6(R)$ Pyr- $(1 \rightarrow 4)-\beta$-D-Glc $p$ NAc- $(1 \rightarrow 3)-\alpha$-L-Fuc $p$. Recent UV, SPR, and TEM studies, using BSA conjugates and gold nanoparticles of the synthetic sulfated disaccharide, clearly demonstrated self-recognition on the disaccha-
\end{abstract}

A. Carvalho de Souza · J. F. G. Vliegenthart • J. P. Kamerling ( $ه)$

Bijvoet Center, Department of Bio-Organic Chemistry,

Utrecht University,

Padualaan 8,

3584 CH Utrecht, The Netherlands

e-mail: j.p.kamerling@uu.nl

D. N. Ganchev

Bijvoet Center, Department of Biochemistry of Membranes,

Utrecht University,

Padualaan 8 ,

$3584 \mathrm{CH}$ Utrecht, The Netherlands

M. M. E. Snel - J. P. J. M. van der Eerden

Department of Physical Chemistry of Interfaces, Debye Institute,

Utrecht University,

Padualaan 8,

3584 CH Utrecht, The Netherlands

Present address:

A. Carvalho de Souza

R\&D Analysis, DSM Food Specialties B.V.,

Alexander Fleminglaan 1,

2613 AX Delft, The Netherlands ride level in the presence of $\mathrm{Ca}^{2+}$-ions. To determine binding forces of the carbohydrate-carbohydrate interactions for both synthetic MAF oligosaccharides, atomic force microscopy (AFM) studies were carried out. It turned out that, in the presence of $\mathrm{Ca}^{2+}$-ions, the force required to separate the tip and sample coated with a self-assembling monolayer of thiol-spacer-containing $\beta$-D-Glc $p$ NAc$(1 \rightarrow 3)-\alpha$-L-Fuc $p-(1 \rightarrow \mathrm{O})\left(\mathrm{CH}_{2}\right)_{3} \mathrm{~S}\left(\mathrm{CH}_{2}\right)_{6} \mathrm{~S}-$ was found to be quantized in integer multiples of $30 \pm 6 \mathrm{pN}$. No binding was observed between the two monolayers in the absence of $\mathrm{Ca}^{2+}$-ions. $\mathrm{Cd}^{2+}$-ions could partially induce the selfinteraction. In contrast, similar AFM experiments with thiol-spacer-containing $\beta$-D-Gal $p 4,6(R) \mathrm{Pyr}-(1 \rightarrow 4)-\beta$-DGlc $p$ NAc- $(1 \rightarrow 3)-\alpha$-L-Fuc $p-(1 \rightarrow \mathrm{O})\left(\mathrm{CH}_{2}\right)_{3} \mathrm{~S}_{(}\left(\mathrm{CH}_{2}\right)_{6} \mathrm{~S}-\operatorname{did}$ not show a binding in the presence of $\mathrm{Ca}^{2+}$-ions. Also TEM experiments of gold nanoparticles coated with the pyruvated trisaccharide could not make visible aggregation in the presence of $\mathrm{Ca}^{2+}$-ions. It is suggested that the selfinteraction between the sulfated disaccharide fragments is stronger than that between the pyruvated trisaccharide.

Keywords Carbohydrate-carbohydrate interactions . Atomic force microscopy · Transmission electron microscopy $\cdot$ Marine sponges $\cdot$ Cell adhesion

\section{Introduction}

Species-specific reaggregation of dissociated marine sponge cells was the first experimental system to provide direct evidence of cell-cell recognition and adhesion mechanisms [1]. Later studies revealed that the speciesspecific cell aggregation of the marine sponge Microciona prolifera is mediated by a proteoglycan-like aggregation 
factor (MAF). Hereby, the N-glycans of two functional domains of MAF, MAFp4 and MAFp3, play an essential role: (i) the MAFp4-bound 6-kDa glycan (known as g-6), which in a $\mathrm{Ca}^{2+}$-independent way adheres to cell surface receptors, and (ii) the MAFp3-bound 200-kDa glycan (known as $\mathrm{g}-200$ ), which promotes cell adhesion via a $\mathrm{Ca}^{2+}$-dependent self-association process $[2,3]$. Specific monoclonal antibodies against purified MAF, called Block 1 and Block 2, could inhibit the $\mathrm{Ca}^{2+}$-dependent self-association process without interfering with the cell-binding activity. These antibodies bind to highly repetitive epitopes (1,100 antigenic sites for Block 1 Fab [4], and 2,500 sites for Block 2 Fab [5]) located on the acidic g-200 glycan. Structural analysis of the isolated epitopes showed a pyruvated trisaccharide $\beta$-DGal $p$,6(R)Pyr-( $(1 \rightarrow 4)-\beta$-D-Glc $p$ NAc- $(1 \rightarrow 3)$-L-Fuc $p 2[6]$ (Block 1) and a sulfated disaccharide $\beta$-D-Glc $p$ NAc3S$(1 \rightarrow 3)$-L-Fucp 1 [7] (Block 2) (Scheme 1). Additional studies on the biopolymer level revealed that the g-200 polysaccharide contains only $\alpha$-L-Fuc $p$ units [8].

Previously, the molecular behaviour of the sulfated disaccharide epitope in the self-aggregation on the MAF level was investigated via mimicking studies in several ways. Ultraviolet (UV) and surface plasmon resonance (SPR) spectroscopy of a synthetic $\beta$-D-Glc $p$ NAc3S- $(1 \rightarrow 3)-\alpha$-LFucp- $(1 \rightarrow \mathrm{O})$ fragment multivalently presented on bovine serum albumin (BSA) strongly supported the existence of true $\mathrm{Ca}^{2+}$-induced carbohydrate-carbohydrate interactions as a major force in the MAF aggregation phenomenon $[9,10]$. Moreover, transmission electron microscopy (TEM) imaging of gold glyconanoparticles coated with $\beta$-D-Glc $p$ NAc3S$(1 \rightarrow 3)$ - $\alpha$-L-Fuc $p$ - $(1 \rightarrow \mathrm{O})\left(\mathrm{CH}_{2}\right)_{3} \mathrm{~S}\left(\mathrm{CH}_{2}\right)_{6} \mathrm{SH} \quad(\mathbf{1 - S H})$ (Scheme 1) and related structures, in the presence or absence of $\mathrm{Ca}^{2+}$-ions, has given valuable information on the mechanism of this disaccharide self-recognition [11, 12].

Nowadays, atomic force microscopy (AFM) is frequently applied to determine interaction forces between biomolecules [13]. Starting with the detection of the first discrete unbinding forces of single molecular bonds [14] by AFM only a few years ago, measurements have become more and more quantitative $[15,16]$. Measurements of binding forces intrinsic to the marine sponge aggregation factors were performed in order to assess their contribution to the maintenance of the anatomic integrity of these multicellular organisms [17, 18]. At physiological $\mathrm{Ca}^{2+}$ concentration, the average adhesive force between two MAF molecules was $125 \mathrm{pN}$, ranging up to $400 \mathrm{pN}$. The frequently observed multiple jump-offs indicated polyvalent binding. Recently, AFM was used to quantify the unbinding forces of a single pair of Lewis x trisaccharides [19].

To investigate in more detail the implied structural role of both the disaccharide $\mathbf{1}$ and trisaccharide $\mathbf{2}$ epitope in the MAF g-200 glycan, we combined the useful aggregation model system of the gold glyconanoparticles using TEM with AFM binding strength measurements, and the results are presented in this study.

\section{Results}

Aggregation and adhesion force measurements of multivalently presented disaccharide 1-SH

In earlier studies, we have shown that the synthetic sulfated disaccharide 1 in its $\alpha$-anomeric form (Scheme 1) can

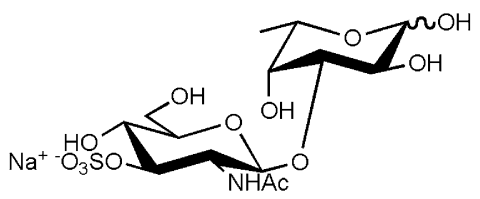

1

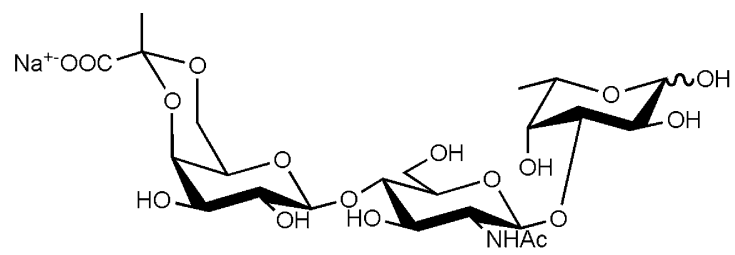

2

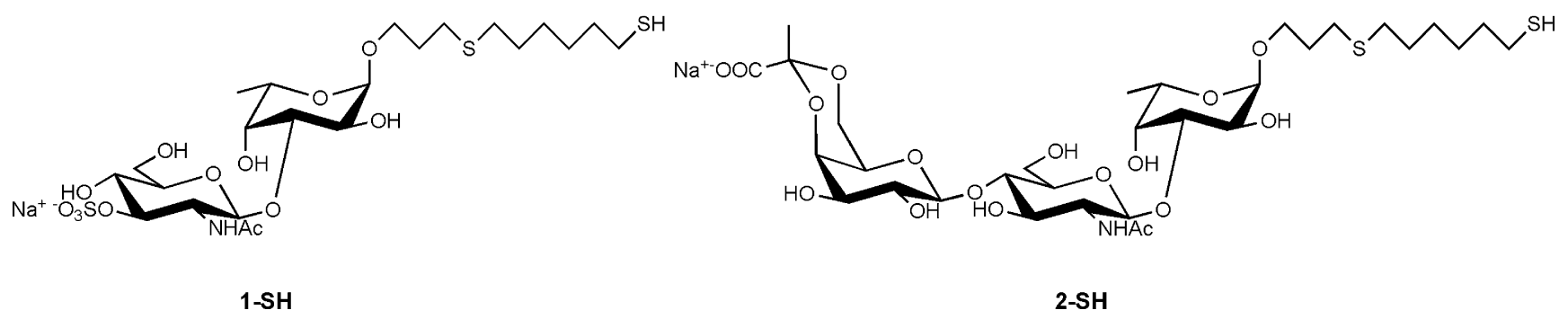

Scheme 1 Structures of the sulfated disaccharide 1 and the pyruvated trisaccharide 2, isolated from MAF g-200 glycan, and of the corresponding synthetic derivatives 1-SH and 2-SH 
mimic the g-200 glycan self-aggregation, when multivalently presented as BSA-conjugates (UV and SPR studies) [10] or as gold glyconanoparticles (TEM studies) [12]. In the latter study, we also demonstrated that various functional groups of the disaccharide were essential for the self-interaction, namely, the methyl group of the Fuc, and the sulfate and $\mathrm{N}$-acetyl group of the GlcNAc moiety. Although also gold nanoparticles decorated with the $\beta$ anomeric form of $\mathbf{1}$ showed self-aggregation, the aggregates were much smaller than those obtained with the $\alpha$ anomeric form of $\mathbf{1}(15 \mathrm{~nm}$ versus $100 \mathrm{~nm})$ [12], indicating the importance of $\alpha$-L-Fuc in the native g-200 [8]. As an illustration, Fig. 1 shows the aggregation behavior of gold glyconanoparticles Au-1 in the absence and presence of $10 \mathrm{mM}$ aqueous $\mathrm{CaCl}_{2}$ [12]. No self-recognition of the disaccharide was observed in the presence of $\mathrm{Mg}^{2+}-$ or $\mathrm{Mn}^{2+}$ ions, whereas in the presence of $\mathrm{Cd}^{2+}$-ions a weaker selfrecognition, compared with $\mathrm{Ca}^{2+}$-ions, was detected.

For the quantitative analysis of the adhesion forces between the synthetic sulfated disaccharide epitopes by AFM, flat gold-surface samples and gold cantilevers were functionalized with self-assembling monolayers (SAMs) of the thiol-spacer-containing sulfated disaccharide 1-SH $(\alpha-$ configuration of L-Fuc). The generated SAMs provided the well-defined polyvalent structures [20] needed to evaluate weak carbohydrate-carbohydrate interactions. Initially, a series of approach-retract cycles were carried out in water and in $10 \mathrm{mM}$ aqueous $\mathrm{CaCl}_{2}$, whereas control experiments were performed with an unfunctionalized gold tip and a functionalized gold-surface sample and vice versa, and both an unfunctionalized gold tip and gold-surface sample. To minimize effects of the possible influence of the density and orientation of the saccharide molecules on the carbohydrate-carbohydrate interaction, approach-retract cycles were performed approximately 300 times in different areas of the monolayer surface sample. In addition, the autocorrelation analysis applied to the resulting data set, in case of interaction, should eliminate the influence of these factors to the adhesion force calculated for the single pair.

As visualized in Fig. 2a for one approach-retract cycle, no interaction was detected between the 1-SH SAM on the tip and on the surface sample, when using water as medium. Detailed analysis of the approach branch of the force-distance curves in water showed that the curve gradually bends before contact (Fig. 2b). This gradual transition from non-contact to contact mode indicates repulsion between the monolayers. The bending may be the result of repulsive forces occurring just before the two negatively charged SAMs get into contact. However, when water was replaced by $10 \mathrm{mM}$ aqueous $\mathrm{CaCl}_{2}$, the forcedistance curves presented the typical features for interactions between biomolecules, with in some cases multiple, stepwise break processes, as is illustrated by the two
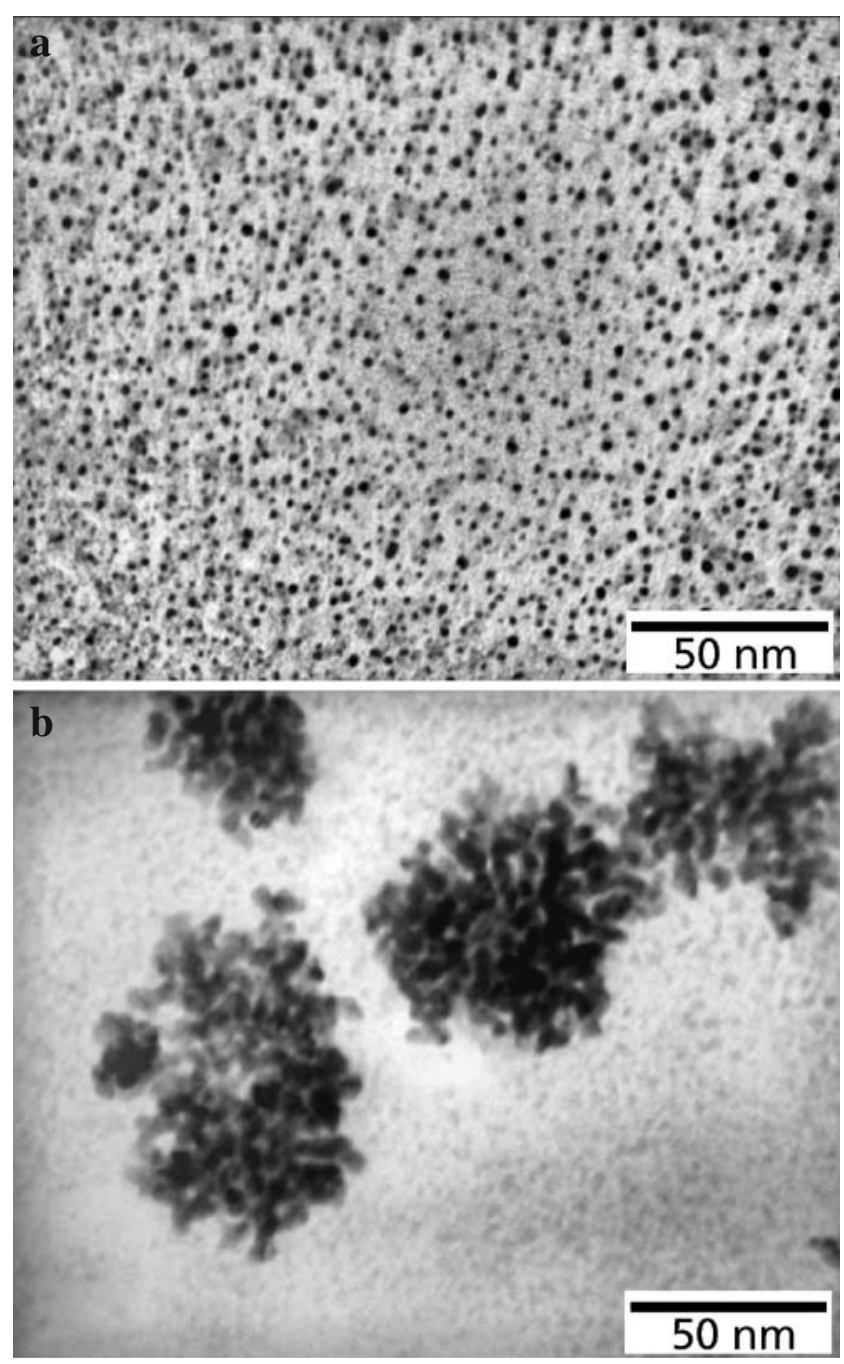

Fig. 1 TEM images of gold nanoparticles decorated with disaccharide 1-SH (Au-1) after different incubation conditions (scale bar $50 \mathrm{~nm}$ ). a Au-1 in water $(0.1 \mathrm{mg} / \mathrm{ml}, 16 \mathrm{~h}$ incubation). b Au-1 in $10 \mathrm{mM}$ aqueous $\mathrm{CaCl}_{2}(0.1 \mathrm{mg} / \mathrm{ml}, 16 \mathrm{~h}$ incubation) [12]

approach-retract cycles depicted in Fig. 2c, d. Here, a sharp transition between non-contact to contact mode is observed. A histogram derived from more than 300 measured final rupture forces [14] revealed eight maxima that represent an integer number of force quantum for the unbinding of a pair of sulfated disaccharide molecules (Fig. 2e). For the analysis, only the last step of unbinding was considered, because it is conceivable that the other steps are nonlinear convolutions of multiple unbinding processes. The autocorrelation analysis of the histogram (Fig. 2f) showed pronounced periodicity of the autocorrelation function indicating that the measured adhesion forces are composed of integer multiples. The calculated force quantum of $30 \pm 6 \mathrm{pN}$ was attributed to the interaction of a single 1-SH pair.

Force-distance curves obtained from the control experiments with an unfunctionalized gold tip and a gold-surface sample functionalized with 1-SH, and vice versa, indicated 


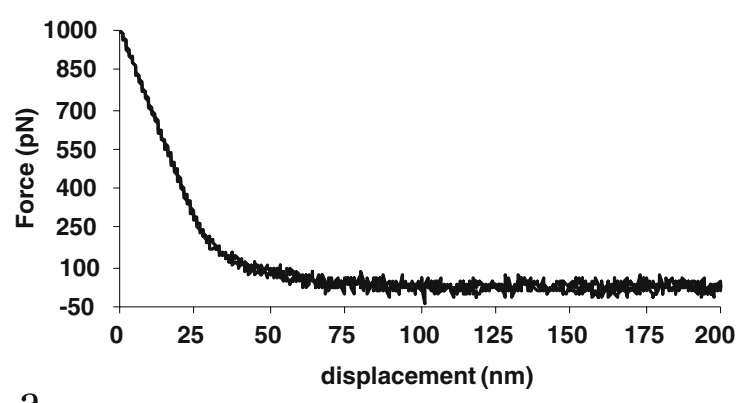

a
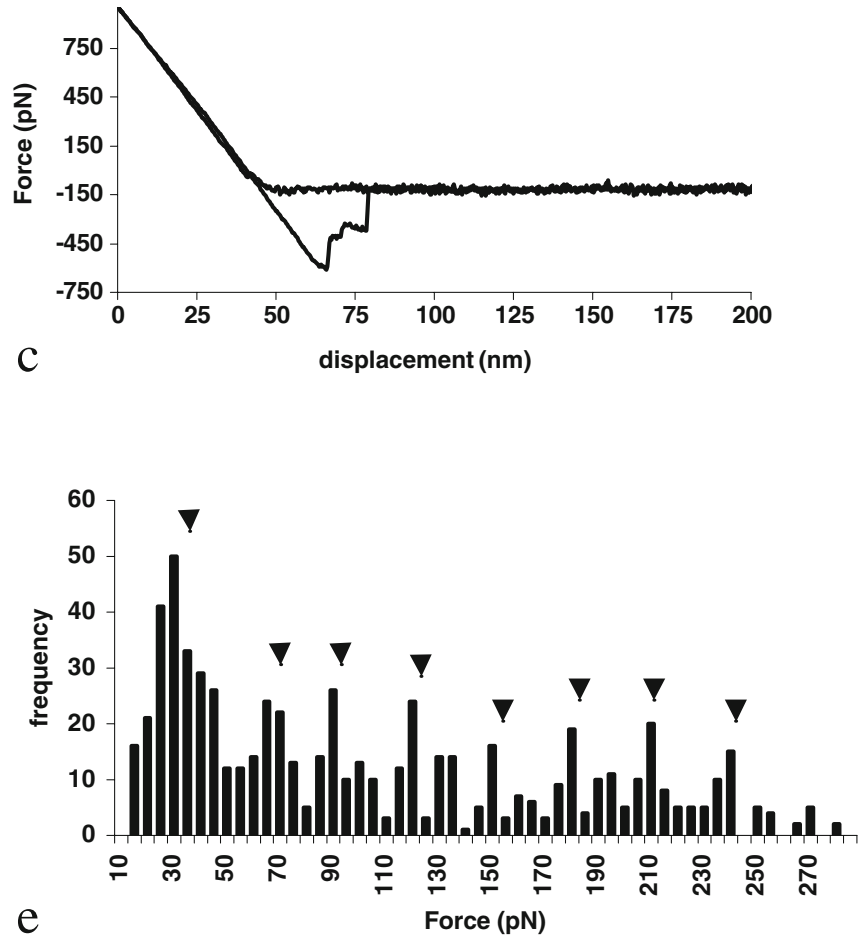

Fig. 2 a Typical AFM force-distance curve obtained with a disaccharide 1-SH functionalized gold tip and a disaccharide 1-SH functionalized gold-surface sample in water. b Detailed section of the force-distance curve depicted in a. c and d, Typical AFM forcedistance curves obtained with a disaccharide 1-SH functionalized gold

that no binding occurs in water (Fig. 3a) nor in $10 \mathrm{mM}$ aqueous $\mathrm{CaCl}_{2}$ (Fig. 3b). However, a close inspection of the approach branches in both media showed a striking difference in the force curves. In water, the approach branch of these curves showed repulsion between the 1-SH sample SAM and the unfunctionalized tip (Fig. 3a), whereas in $10 \mathrm{mM}$ aqueous $\mathrm{CaCl}_{2}$ such a repulsion was not observed (Fig. 3b). In these control experiments the addition of $\mathrm{Ca}^{2+}$-ions seems to eradicate the repulsion between the gold layers and the negatively charged SAMs.

From these observations it was concluded that the $\mathrm{Ca}^{2+}$. ions seem to be involved in the stabilization of the self-
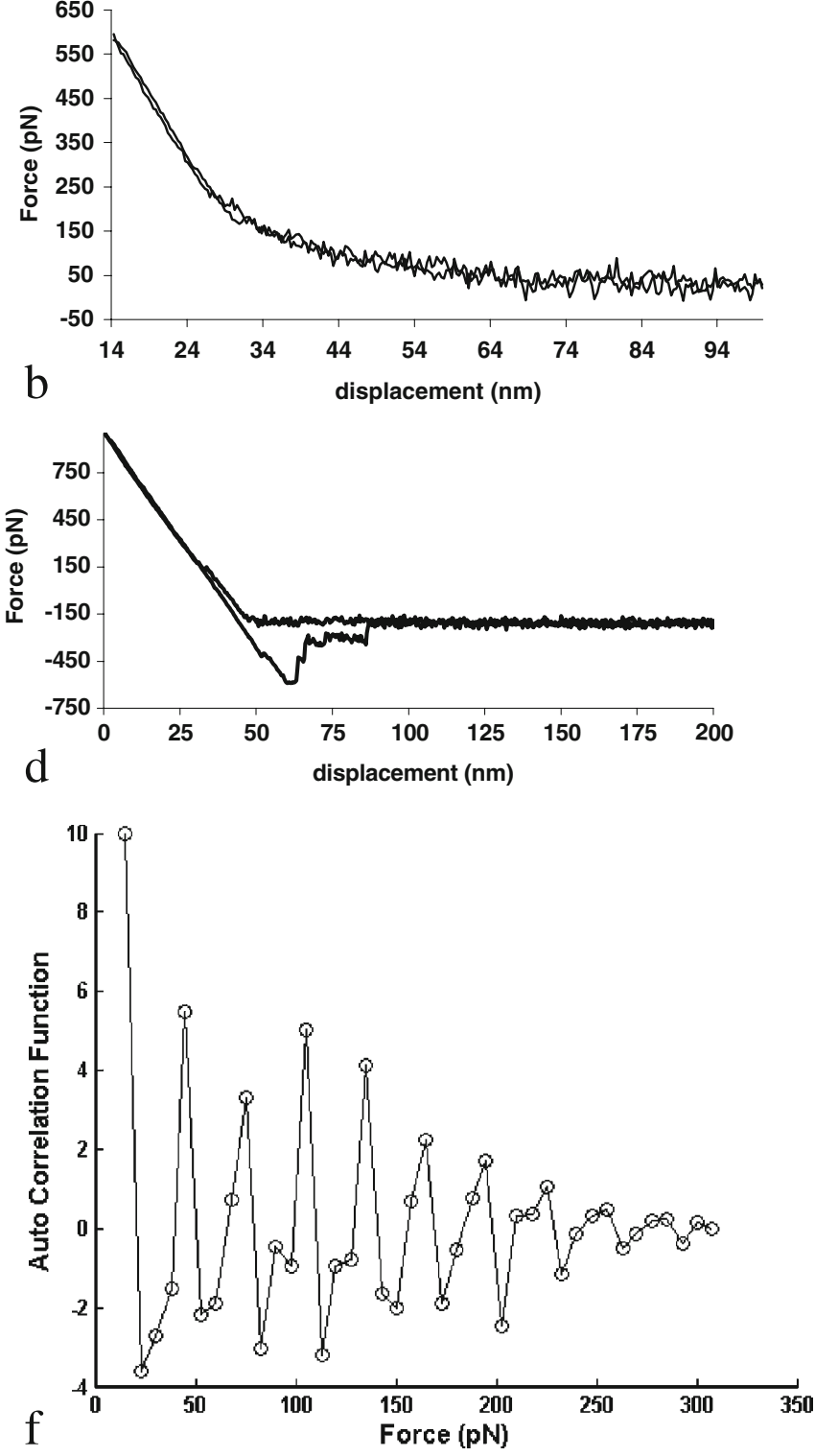

tip and a disaccharide 1-SH functionalized gold-surface sample in $10 \mathrm{mM}$ aqueous $\mathrm{CaCl}_{2}$. e Histogram of the adhesion forces between the disaccharide 1-SH functionalized tip and surface sample in $10 \mathrm{mM}$ aqueous $\mathrm{CaCl}_{2}$. $\mathbf{f}$ Autocorrelation analysis of the histogram in $\mathbf{e}$

interaction of the sulfated disaccharide, although not only based on the neutralization of the negatively charged sulfate groups on the disaccharide.

The control experiments with two unfunctionalized gold layers resulted in force-distance curves typical for interactions wherein biomolecules are not involved. Here, a pronounced and linear force-distance dependence was observed in the retracting branch of the curve typical for an inelastic system with a strong short-range interaction [18].

As reported previously, the $\mathrm{Ca}^{2+}$ requirements for the MAF activity is very specific, and could only partially be substituted by the transition elements $\mathrm{Mn}^{2+}$ and $\mathrm{Cd}^{2+}$ at 

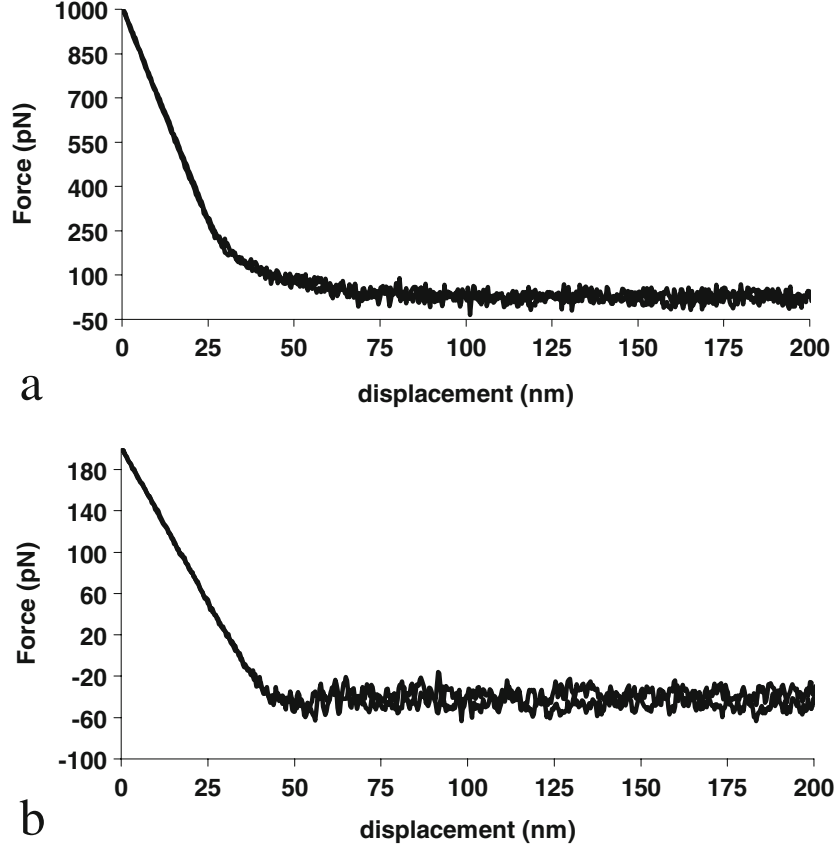

Fig. 3 a Typical AFM force-distance curve obtained with an unfunctionalized gold tip and a disaccharide 1-SH functionalized gold-surface sample in water. b Typical AFM force-distance curve obtained with an unfunctionalized tip and a disaccharide 1-SH functionalized surface sample in $10 \mathrm{mM}$ aqueous $\mathrm{CaCl}_{2}$
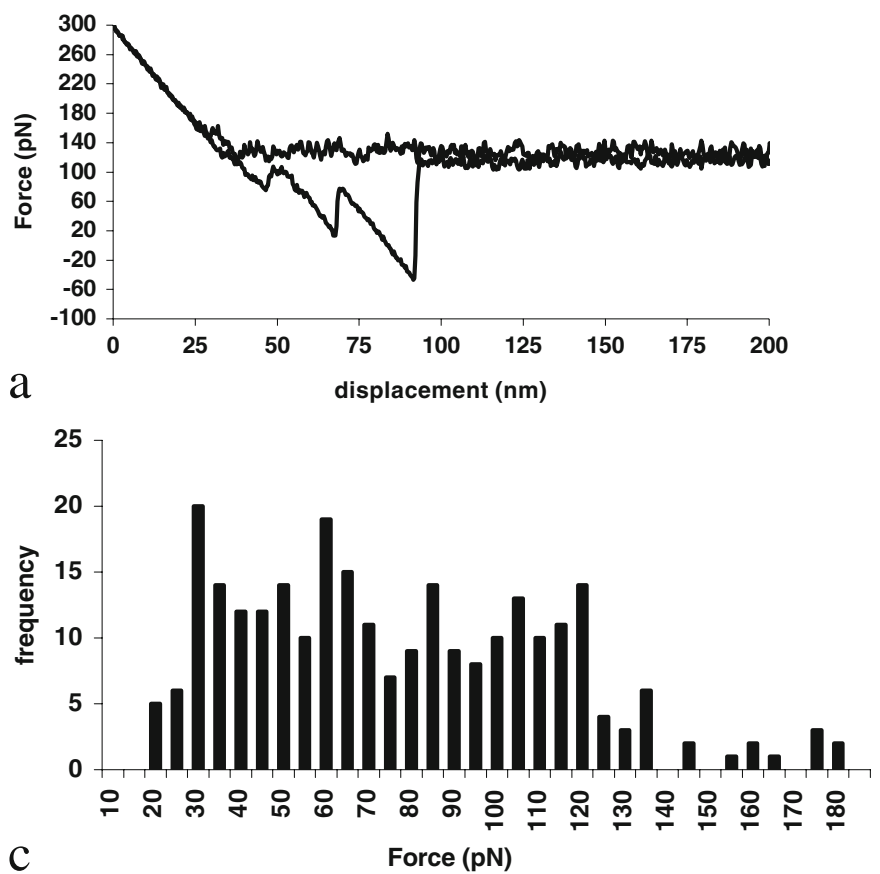

Fig. 4 a, b Typical AFM force-distance curves obtained with a disaccharide 1-SH functionalized gold tip and a disaccharide 1-SH functionalized gold-surface sample in $10 \mathrm{mM}$ aqueous $\mathrm{CdCl}_{2}$. c Histogram of the adhesion forces between the disaccharide 1-SH higher concentrations than $\mathrm{Ca}^{2+}$, and by all of the 15 available lanthanides at lower concentrations than $\mathrm{Ca}^{2+}$ [21]. Of the transition elements, $\mathrm{Cd}^{2+}$-ions have been shown to be the best, supporting a maximum of $50 \%$ of the MAF activity at a concentration range of $50-100 \mathrm{mM}$. Alkaline earth cations such as $\mathrm{Mg}^{2+}, \mathrm{Sr}^{2+}$, or $\mathrm{Ba}^{2+}$ could not replace $\mathrm{Ca}^{2+}$ as an aggregation-mediating agent. In view of these MAF literature data and our findings with $\mathrm{Cd}^{2+}$ - and $\mathrm{Mg}^{2+}$-ions on the disaccharide level in UV, SPR [10] and TEM [12] studies, $\mathrm{CdCl}_{2}$ and $\mathrm{MgCl}_{2}$ were also included in the present AFM studies. Firstly, a series of approach-retract cycles with the tip and surface sample functionalized with a 1-SH SAM were performed in $10 \mathrm{mM}$ aqueous $\mathrm{CdCl}_{2}$. As is evident from Fig. 4a,b, the force-distance curves obtained in the presence of $\mathrm{Cd}^{2+}$-ions have the same features as those observed in the presence of $\mathrm{Ca}^{2+}$-ions. The histogram derived from more than 200 measured final ruptures (Fig. 4c) is shifted to lower forces. However, the peaks in the autocorrelation function are not meaningful enough to assure this value as the force quantum. In contrast to the experiments carried out in the presence of $\mathrm{Ca}^{2+}$-ions, showing a frequency of binding contacts of approximately $95 \%$, the experiments containing $\mathrm{Cd}^{2+}$-ions revealed a frequency of binding contacts of only $30 \%$. A likely explanation for these events is that $\mathrm{Cd}^{2+}$-ions are less efficient than $\mathrm{Ca}^{2+}$-ions in initiating the selfrecognition of the sulfated disaccharide. Secondly, an experiment of over 200 approach-retract cycles, performed
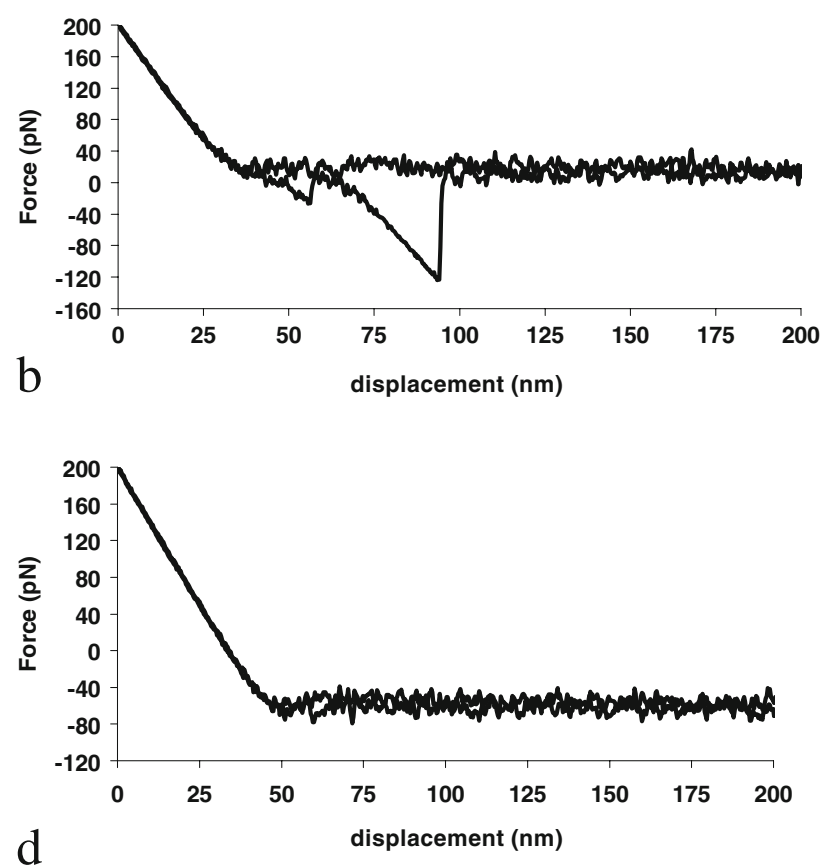

functionalized tip and surface sample in $10 \mathrm{mM}$ aqueous $\mathrm{CdCl}_{2}$. d Typical AFM force-distance curve obtained with a disaccharide 1-SH functionalized tip and a disaccharide 1-SH functionalized surface sample in $10 \mathrm{mM}$ aqueous $\mathrm{MgCl}_{2}$ 
with the tip and surface sample functionalized with a 1-SH $\mathrm{SAM}$ in the presence of $10 \mathrm{mM}$ aqueous $\mathrm{MgCl}_{2}$ (for one cycle, see Fig. 4d), showed a suppression of the repulsion between the two SAMs, but no binding was observed. Based on these observations, one can conclude that $\mathrm{Ca}^{2+}$ ions are not only important for the first step of the selfrecognition process, but also necessary to stabilize the interaction between the pair disaccharides.

Aggregation and adhesion force measurements of multivalently presented trisaccharide 2-SH

To investigate the molecular behaviour of the pyruvated trisaccharide epitope in the carbohydrate-carbohydrate selfrecognition process on the AFM level via a mimicking study, the thiol-spacer-containing compound 2-SH and the derived gold nanoparticles Au-2 were used in the various TEM and AFM studies. Based on the results of the gold glyconanoparticles studies performed with $\mathbf{1}$, the studies with $\mathbf{2}$ were only carried out with L-Fuc in the $\alpha$-anomeric form.

To study the self-recognition capacity of Au-2 by TEM several imaging experiments were carried out. The micrographs of aliquots of Au-2 in water $(0.1 \mathrm{mg} / \mathrm{ml})$ showed uniformly dispersed nanoparticles throughout the grid surface, and no aggregates were observed (Fig. 5a). In a similar way, incubation of Au-2 for $16 \mathrm{~h}$ in $10 \mathrm{mM}$ aqueous $\mathrm{CaCl}_{2}$ did not lead to aggregation of the particles (Fig. 5b). To assure the presence of carboxylate groups in the particles, the latter experiment was repeated at $\mathrm{pH} 8.0$, however, it did not lead to any aggregate formation. Comparable results were obtained for incubation times of 7 days in $10 \mathrm{mM}$ aqueous $\mathrm{CaCl}_{2}$, and for $16 \mathrm{~h}$ incubation in either $20 \mathrm{mM}$ aqueous $\mathrm{CaCl}_{2}$ or $10 \mathrm{mM}$ aqueous $\mathrm{MgCl}_{2}$. The possible influence of the particles concentration to its aggregation capacity was investigated by increasing the Au-2 concentration from 0.1 to $1 \mathrm{mg} / \mathrm{ml}$ in a 16 -h incubation in $10 \mathrm{mM}$ aqueous $\mathrm{CaCl}_{2}$. However, also in this case no aggregates were observed in the TEM micrographs obtained.

Additional AFM experiments using flat gold-surface samples and gold cantilevers functionalized with SAMs of the 2-SH confirmed the TEM findings. Only nonbinding contacts were observed for more than 300 approach-retract cycles in different locations throughout the 2-SH SAM surface, as illustrated by the force-distance curves obtained in water (for one approachretract cycle, see Fig. 6a), and in $10 \mathrm{mM}$ aqueous $\mathrm{CaCl}_{2}$ (for one approach-retract cycle, see Fig. 6b), respectively.

Adhesion force measurements of multivalently presented disaccharide 1-SH (tip) and trisaccharide 2-SH (sample)

In order to check if a heterotopic recognition between the sulfated disaccharide and the pyruvated trisaccharide exists, crossreactivity experiments were carried out between SAMs formed
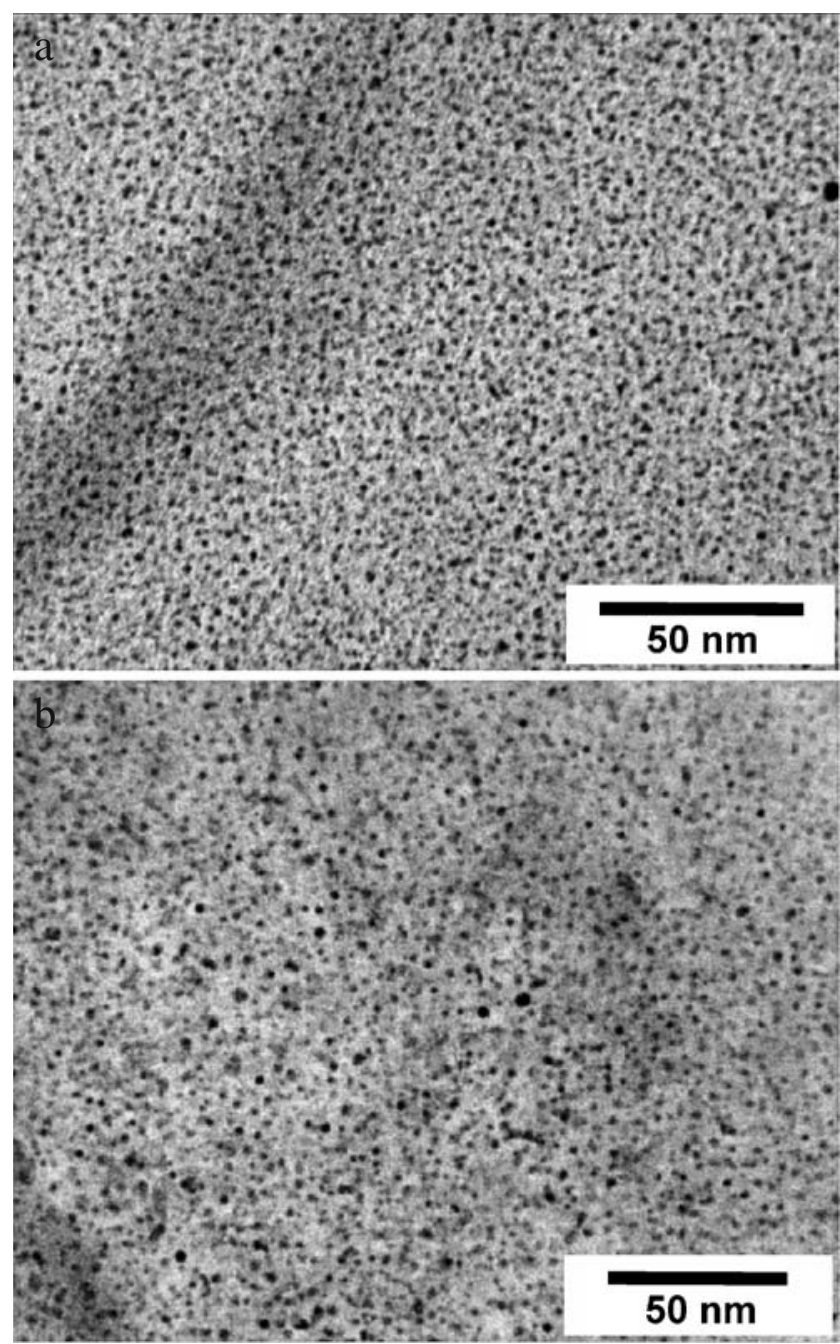

Fig. 5 TEM images of gold nanoparticles decorated with trisaccharide 2-SH (Au-2) after different incubation conditions (scale bar $50 \mathrm{~nm})$. a Au-2 in water $(0.1 \mathrm{mg} / \mathrm{ml}, 16 \mathrm{~h}$ incubation). b Au-2 in $10 \mathrm{mM}$ aqueous $\mathrm{CaCl}_{2}(0.1 \mathrm{mg} / \mathrm{ml}, 16 \mathrm{~h}$ incubation $)$

with 1-SH and 2-SH. The force-distance curves obtained from the experiments with a tip functionalized with 1-SH and a surface sample functionalized with $\mathbf{2 - S H}$, and vice versa, showed no binding in water nor in $10 \mathrm{mM}$ aqueous $\mathrm{CaCl}_{2}$.

\section{Discussion}

In summarizing our results of the present investigation, it is clear that a surprising difference exists between the activity of the synthetic sulfated disaccharide $\mathbf{1}$ and the synthetic pyruvated trisaccharide 2 in mimicking the MAF g-200 self-aggregation. On one hand, TEM and AFM studies of the multivalently presented disaccharide showed a clear homotopic carbohydrate-carbohydrate interaction in the presence of $\mathrm{Ca}^{2+}$-ions. On the other hand, similar studies carried out with the multivalently presented trisaccharide 


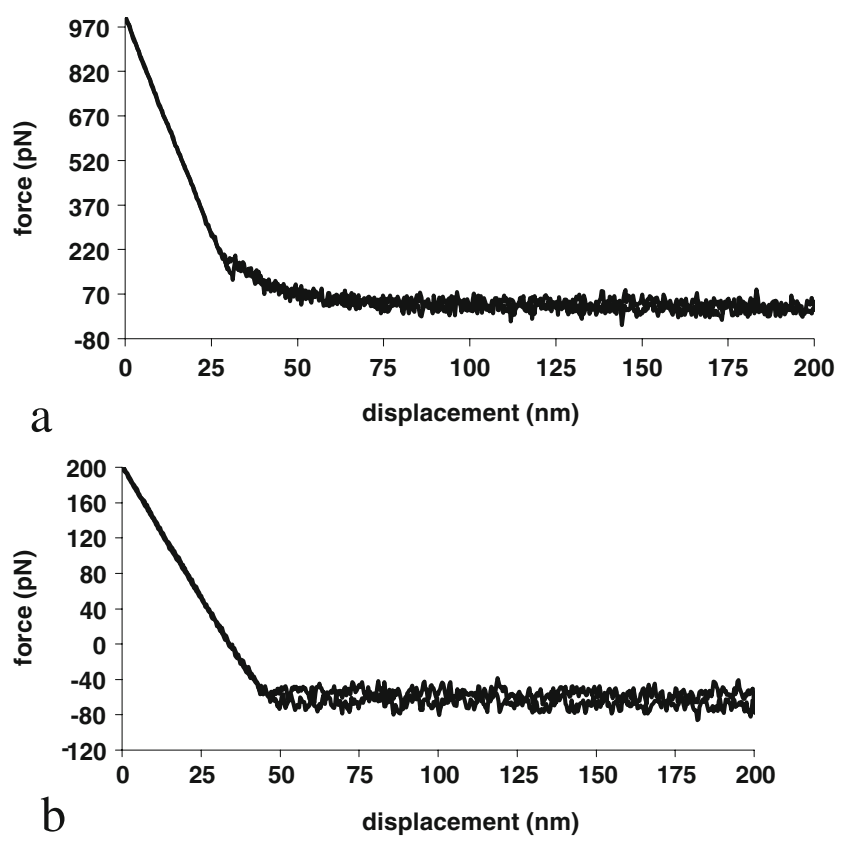

Fig. 6 a Typical AFM force-distance curve obtained with a trisaccharide 2-SH functionalized gold tip and a trisaccharide 2-SH functionalized gold-surface sample in water. b Typical AFM forcedistance curve obtained with a trisaccharide 2-SH functionalized gold tip and a trisaccharide 2-SH functionalized gold-surface sample in $10 \mathrm{mM}$ aqueous $\mathrm{CaCl}_{2}$

showed, in the presence of $\mathrm{Ca}^{2+}$-ions, no self-aggregation of the gold glyconanoparticles and only nonbinding contacts between the self-assembling monolayers.

In our earlier reported TEM studies with gold nanoparticles decorated with the thiol-spacer-containing sulfated disaccharide 1-SH (Au-1) [12], it was hypothesized that the coordination of $\mathrm{Ca}^{2+}$-ions by different functionalities of the carbohydrate backbone would provide the adequate conformational changes making possible other interactions to stabilize the whole complex. The additional information generated by the present AFM measurements reinforces our previous suggestions. First of all, without $\mathrm{Ca}^{2+}$-ions, the repulsive forces between two sodiated sulfated disaccharide molecules suppress the formation of interactions. However, only repulsive forces elimination is not enough to assure binding, as observed in the experiments with $\mathrm{Mg}^{2+}$-ions. After elimination of the repulsive barrier, subsequent coordination of the $\mathrm{Ca}^{2+}$-ions to different sites of the disaccharide backbone will probably lead to a favorable conformation where strong attractive forces, such as hydrophobic contacts and hydrogen bridges, can occur. $\mathrm{Cd}^{2+}$-ions can emulate the ability of $\mathrm{Ca}^{2+}$-ions to initiate and stabilize the interaction, nevertheless with a lower efficiency. It should be noted that the force quantum of $30 \pm 6 \mathrm{pN}$, found for the 1-SH-1-SH self-recognition, is higher than the force quantum found for the $\mathrm{Le}^{\mathrm{x}}-\mathrm{Le}^{\mathrm{x}}$ self-recognition $(20 \pm 4 \mathrm{pN})[19]$.
Even though the pyruvated trisaccharide $\mathbf{2}$ is the epitope recognized by the monoclonal antibody Block 1, which is able to inhibit the $\mathrm{Ca}^{2+}$-dependent MAF self-association, gold nanoparticles coated with the thiol-spacer-containing epitope 2-SH (Au-2) do not aggregate in the presence of $\mathrm{Ca}^{2+}$-ions. Changing the conditions in terms of $\mathrm{pH}$, incubation time, molarity of $\mathrm{CaCl}_{2}$, or concentration of particles, did not give rise to the expected self-recognition. Of course, a first-line conclusion could be that the role of the trisaccharide epitope in the $\mathrm{Ca}^{2+}$-dependent MAF g-200 self-association is not related to homotopic carbohydratecarbohydrate interactions, as shown to be the case for the disaccharide. In order to check the possibility of a heterotopic carbohydrate-carbohydrate interaction (for reviews of such interactions, see refs. [22] and [23]), cross-reactivity AFM experiments with SAMs of 1-SH and 2-SH were carried out. But also here only nonbinding contacts were observed, suggesting that these epitopes do not interact with each other during the $\mathrm{Ca}^{2+}$-dependent MAF g-200 self-recognition. Evaluation of the various findings on the biopolymer and the oligosaccharide level leads to the preliminary conclusion that the used approaches are not sensitive enough to visualize and measure the selfrecognition of the pyruvated trisaccharide, meaning that its carbohydrate-carbohydrate interaction is much weaker than that of the sulfated disaccharide self-recognition. In this context it is interesting to memorize that our earlier SPR study with a BSA conjugate of the $\mathrm{Le}^{\mathrm{x}}$ epitope (loading: $n=$ 13) did not show the $\mathrm{Ca}^{2+}$-dependent self-recognition at concentrations up to $100 \mu \mathrm{M}$, probably due to a significantly lower density and concentration of the $\mathrm{Le}^{\mathrm{x}}$ epitope, when compared with the literature data [10].

Taking all data obtained for the sulfated disaccharide and the pyruvated trisaccharide together, it can be concluded that important new steps have been set to a further understanding on the molecular level of the carbohydrate-mediated MAF self-association. In our search to more sensitive technologies to visualize carbohydrate-carbohydrate interactions, our future investigations will be focused on the use of NMR spectroscopy in studying interactions between gold nanoparticles decorated with the sulfated disaccharide or the pyruvated trisaccharide and the related free epitopes in the presence and absence of $\mathrm{Ca}^{2+}$-ions. Furthermore, modeling studies should shed light on the specificity of the presence of $\mathrm{Ca}^{2+}$-ions in the interaction phenomenon.

\section{Experimental section}

Preparation of thiol-spacer-containing oligosaccharides

The syntheses of the thiol-spacer-containing disaccharide $\beta$-D-Glc $p$ NAc $3 S$ - $(1 \rightarrow 3)-\alpha-\mathrm{L}-\mathrm{Fuc} p-(1 \rightarrow \mathrm{O})\left(\mathrm{CH}_{2}\right)_{3} \mathrm{~S}$ 
$\left(\mathrm{CH}_{2}\right)_{6} \mathrm{SH}$ (1-SH) and trisaccharide $\beta$-D-Galp4,6(R)Pyr$(1 \rightarrow 4)$ - $\beta$-D-Glc $p$ NAc- $(1 \rightarrow 3)-\alpha$-L-Fuc $p-(1 \rightarrow \mathrm{O})\left(\mathrm{CH}_{2}\right)_{3} \mathrm{~S}$ $\left(\mathrm{CH}_{2}\right)_{6} \mathrm{SH}(\mathbf{2}-\mathrm{SH})$ (Scheme 1) have been described earlier $[11,24]$.

\section{Atomic force microscopy}

Atomically flat mica plates were made biocompatible with a chromium layer $(2.5 \mathrm{~nm})$ on which a gold layer $(200 \mathrm{~nm})$ was deposited by evaporation in high vacuum. Prior to use, gold surfaces were annealed for $2 \mathrm{~min}$ in a gas flame to obtain $\mathrm{Au}(111)$ terraces [25]. Commercial silicon nitride rectangular cantilevers with $\mathrm{V}$-shaped gold-coated tip (Olympus, Bio-Lever series; gold coating at both sides of the tip varying from 20 to $30 \mathrm{~nm}$ ) and nominal spring constant $0.03 \mathrm{~N} / \mathrm{m}$ were used. The cantilevers and the goldsurface samples were functionalized with the thiol-spacercontaining oligosaccharides 1-SH and 2-SH. To this end they were immersed for $2 \mathrm{~h}$ in $1 \mathrm{mM}$ carbohydrate solutions in methanol (cantilever) or water (surface), rinsed several times with water, and dried under a stream of argon. The samples were mounted on an E-scanner, which was calibrated on a standard grid of a Nanoscope III multimode AFM (Digital Instruments, Santa Barbara, CA, USA) instrument. Force-distance interaction measurements were performed in water, $10 \mathrm{mM}$ aqueous $\mathrm{CaCl}_{2}, 10 \mathrm{mM}$ aqueous $\mathrm{CdCl}_{2}$, and $10 \mathrm{mM}$ aqueous $\mathrm{MgCl}_{2}$ with a fluid cell without O-ring. Unloading rates of $400 \mathrm{~nm} / \mathrm{s}$ and ramp sizes of $200 \mathrm{~nm}$ were used.

\section{Transmission electron microscopy}

The generation of the 1-SH-and 2-SH-decorated gold nanoparticles $\beta$-D-Glc $p$ NAc3 $S$ - $(1 \rightarrow 3)-\alpha$-L-Fuc $p-(1 \rightarrow \mathrm{O})$ $\left(\mathrm{CH}_{2}\right)_{3} \mathrm{~S}\left(\mathrm{CH}_{2}\right)_{6} \mathrm{~S}-@-\mathrm{Au}$ (Au-1) and $\beta$-D-Gal $p 4,6(R) \mathrm{Pyr}-$ $(1 \rightarrow 4)-\beta$-D-Glc $p$ NAc- $(1 \rightarrow 3)-\alpha$-L-Fuc $p-(1 \rightarrow \mathrm{O})\left(\mathrm{CH}_{2}\right)_{3} \mathrm{~S}$ $\left(\mathrm{CH}_{2}\right)_{6} \mathrm{~S}-@-\mathrm{Au}(\mathrm{Au}-2)$ have been reported earlier $[11,24]$. The mean diameter and the carbohydrate-weight percentage of the particles are $1.82 \pm 0.8 \mathrm{~nm}(36 \%)$ for $\mathbf{A u}-\mathbf{1}$, and $1.59 \pm$ $0.5 \mathrm{~nm}$ (53\%) for Au-2. TEM images were obtained with a Philips Tecnai 12 microscope at $120 \mathrm{kV}$ accelerating voltage. For a typical experiment in water, a single drop $(1 \mu \mathrm{l})$ of an aqueous gold glyconanoparticle solution $(0.1 \mathrm{mg} / \mathrm{ml})$ was deposited onto a carbon-coated copper grid (QUANTIFOIL on 200 square mesh copper grid, hole shape $\mathrm{R} 2 / 2$ ), and allowed to dry at room temperature for several hours. Experiments, whereby water was replaced by either $10 \mathrm{mM}$ aqueous $\mathrm{CaCl}_{2}$ or $10 \mathrm{mM}$ aqueous $\mathrm{MgCl}_{2}$, were performed following the same procedure. Initially, aliquots of gold glyconanoparticles Au-2 $(0.1 \mathrm{mg} / \mathrm{ml})$ were incubated in $10 \mathrm{mM}$ aqueous $\mathrm{CaCl}_{2}$ for $16 \mathrm{~h}$ and 7 days, then examined. The same procedure was repeated in $10 \mathrm{mM}$ aqueous $\mathrm{CaCl}_{2}$ adjusted to $\mathrm{pH} 8.0$ with $0.01 \mathrm{M}$ aqueous $\mathrm{NaOH}$. Additionally, aliquots of Au-2 were incubated at $0.1 \mathrm{mg} / \mathrm{ml}$ concentration in $20 \mathrm{mM}$ aqueous $\mathrm{CaCl}_{2}$ and at $1 \mathrm{mg} / \mathrm{ml}$ concentration in $10 \mathrm{mM}$ aqueous $\mathrm{CaCl}_{2}$, both for $16 \mathrm{~h}$ prior to examination. Furthermore, aliquots of Au-2 were incubated at $0.1 \mathrm{mg} / \mathrm{ml}$ concentration in $10 \mathrm{mM}$ aqueous $\mathrm{MgCl}_{2}$ for $16 \mathrm{~h}$, then examined. For experimental details with respect to the Au-1 particles, see Ref. [12].

Acknowledgement We thank the European Commission for financial support; Glycogold project, Contact No: MRTN-CT-2004005645 .

Open Access This article is distributed under the terms of the Creative Commons Attribution Noncommercial License which permits any noncommercial use, distribution, and reproduction in any medium, provided the original author(s) and source are credited.

\section{References}

1. Wilson, H.V.: On some phenomena of coalescence and regeneration in sponges. J. Exp. Zool. 5, 245-258 (1907). doi:10.1002/ jez. 1400050204

2. Jarchow, J., Fritz, J., Anselmetti, D., Calabro, A., Hascall, V.C., Gerosa, D., Burger, M.M., Fernàndez-Busquets, X.: Supramolecular structure of a new family of circular proteoglycans mediating cell adhesion in sponges. J. Struct. Biol. 132, 95-105 (2000). doi:10.1006/jsbi.2000.4309

3. Fernàndez-Busquets, X., Burger, M.M.: Circular proteoglycans from sponges: first members of the spongican family. Cell. Mol. Life Sci. 60, 88-112 (2003). doi:10.1007/s000180300006

4. Misevic, G.N., Finne, J., Burger, M.M.: Involvement of carbohydrates as multiple low affinity interaction sites in the selfassociation of the aggregation factor from the marine sponge Microciona prolifera. J. Biol. Chem. 262, 5870-5877 (1987)

5. Misevic, G.N., Burger, M.M.: Carbohydrate-carbohydrate interactions of a novel acidic glycan can mediate sponge cell adhesion. J. Biol. Chem. 268, 4922-4929 (1993)

6. Spillmann, D., Hård, K., Thomas-Oates, J., Vliegenthart, J.F.G., Misevic, G., Burger, M.M., Finne, J.: Characterization of a novel pyruvylated carbohydrate unit implicated in the cell aggregation of the marine sponge Microciona prolifera. J. Biol. Chem. 268, 13378-13387 (1993)

7. Spillmann, D., Thomas-Oates, J.E., van Kuik, J.A., Vliegenthart, J.F.G., Misevic, G., Burger, M.M., Finne, J.: Characterization of a novel sulfated carbohydrate unit implicated in the carbohydratecarbohydrate-mediated cell aggregation of the marine sponge Microciona prolifera. J. Biol. Chem. 270, 5089-5097 (1995). doi:10.1074/jbc.270.10.5089

8. Misevic, G.N., Guerardel, Y., Sumanovski, L.T., Slomianny, M.-C., Demarty, M., Ripoll, C., Karamanos, Y., Maes, E., Popescu, O., Strecker, G.: Molecular recognition between glyconectins as an adhesion self-assembly pathway to multicellularity. J. Biol. Chem. 279, 15579-15590 (2004). doi:10.1074/jbc.M308927200

9. Vermeer, H.J., Kamerling, J.P., Vliegenthart, J.F.G.: Synthesis and conjugation of a sulfated disaccharide involved in the aggregation process of the marine sponge Microciona prolifera. Tetrahedron Asymmetry 11，539-547 (2000). doi:10.1016/S0957-4166(99) 00585-6

10. Haseley, S.R., Vermeer, H.J., Kamerling, J.P., Vliegenthart, J.F.G.: Carbohydrate self-recognition mediates marine sponge cellular 
adhesion. Proc. Natl. Acad. Sci. U.S.A. 98, 9419-9424 (2001). doi:10.1073/pnas. 151111298

11. Carvalho de Souza, A., Halkes, K.M., Meeldijk, J.D., Verkleij, A.J., Vliegenthart, J.F.G., Kamerling, J.P.: Synthesis of gold glyconanoparticles: possible probes for the exploration of carbohydratemediated self-recognition of marine sponge cells. Eur. J. Org. Chem. 4323-4339 (2004). doi:10.1002/ejoc.200400255

12. Carvalho de Souza, A., Halkes, K.M., Meeldijk, J.D., Verkleij, A.J., Vliegenthart, J.F.G., Kamerling, J.P.: Gold glyconanoparticles as probes to explore the carbohydrate-mediated self-recognition of marine sponge cells. ChemBioChem 6, 828-831 (2005). doi:10.1002/cbic. 200400380

13. Willemsen, O.H., Snel, M.M.E., Cambi, A., Greve, J., De Grooth, B.G., Figdor, C.G.: Biomolecular interactions measured by atomic force microscopy. Biophys. J. 79, 3267-3281 (2000)

14. Florin, E.L., Moy, V.T., Gaub, H.E.: Adhesion forces between individual ligand-receptor pairs. Science 264, 415-417 (1994). doi:10.1126/science. 8153628

15. Merkel, R., Nassoy, P., Leung, A., Ritchie, K., Evans, E.: Energy landscapes of receptor-ligand bonds explored with dynamic force spectroscopy. Nature 397, 50-53 (1999). doi:10.1038/16219

16. Evans, E.: Looking inside molecular bonds at biological interfaces with dynamic force spectroscopy. Biophys. Chem. 82, 83-97 (1999). doi:10.1016/S0301-4622(99)00108-8

17. Dammer, U., Popescu, O., Wagner, P., Anselmetti, D., Güntherodt, H.-J., Misevic, G.N.: Binding strength between cell adhesion proteoglycans measured by atomic force microscopy. Science 267, 1173-1175 (1995). doi:10.1126/science.7855599

18. Fritz, J., Anselmetti, D., Jarchow, J., Fernàndez-Busquets, X.: Probing single biomolecules with atomic force microscopy. J. Struct. Biol. 119, 165-171 (1997). doi:10.1006/jsbi.1997.3887
19. Tromas, C., Rojo, J., de la Fuente, J.M., Barrientos, A.G., García, R., Penadés, S.: Adhesion forces between Lewis ${ }^{\mathrm{X}}$ determinant antigens as measured by atomic force microscopy. Angew. Chem. Int. Ed. 40, 3052-3055 (2001). doi:10.1002/1521-3773 (20010817)40:16<3052::AID-ANIE3052>3.0.CO;2-Q

20. Ulman, A.: Formation and structure of self-assembled monolayers. Chem. Rev. 96, 1533-1554 (1996). doi:10.1021/ cr9502357

21. Rice, D.J., Humphreys, T.: Two $\mathrm{Ca}^{2+}$ functions are demonstrated by the substitution of specific divalent and lanthanide cations for the $\mathrm{Ca}^{2+}$ required by the aggregation factor complex from the marine sponge, Microciona prolifera. J. Biol. Chem. 258, 63946399 (1983)

22. Hakomori, S.: Carbohydrate-to-carbohydrate interaction in basic cell biology: a brief overview. Arch. Biochem. Biophys. 426, 173-181 (2004). doi:10.1016/j.abb.2004.02.032

23. Hakomori, S.: Carbohydrate-to-carbohydrate interaction, through glycosynapse, as a basis of cell recognition and membrane organization. Glycoconj. J. 21, 125-137 (2004). doi:10.1023/B: GLYC.0000044844.95878.cf

24. Carvalho de Souza, A., Vliegenthart, J.F.G., Kamerling, J.P.: Gold nanoparticles coated with a pyruvated trisaccharide epitope of the extracellular proteoglycan of Microciona prolifera as potential tools to explore carbohydrate-mediated cell recognition. Org. Biomol. Chem. 6, 2095-2102 (2008). doi:10.1039/ b802235f

25. Casero, E., Vázquez, L., Martín-Benito, J., Morcillo, M.A., Lorenzo, E., Pariente, F.: Immobilization of metallothionein on gold/mica surfaces: Relationship between surface morphology and protein-substrate interaction. Langmuir 18, 5909-5920 (2002). doi:10.1021/la025712c 